\title{
O PENSAMENTO DE CELSO FURTADO: CRENÇAS E DESILUSÕES
}

\author{
Alcides Goularti Filho*
}

O texto tem por objetivo mostrar as contribuições do pensamento de Celso Furtado nos diferentes períodos da economia brasileira nos últimos cinqüenta anos. Nesse período, o Brasil se industrializou, porém manteve a mesma estrutura social desigual. Diante dessa contradição, as análises de Furtado sobre o desenvolvimento brasileiro também sofreram mudanças. Além da introdução, que apresentará os pilares intelectuais de Furtado e o seu contexto histórico, o texto discutirá: a) as origens do subdesenvolvimento brasileiro, concentradas basicamente na obra Formação econômica do Brasil; b) a sua crença na industrialização como o caminho para o desenvolvimento, analisada em Desenvolvimento e subdesenvolvimento; c) a sua desilusão em relação à industrialização na periferia, discutida inicialmente em Um projeto para o Brasil, aprofundada em Análise do "modelo" brasileiro e acabada em $O$ mito do desenvolvimento econômico - quando incorpora a tese da dependência cultural -; d) o seu sentimento de angústia quando vê o desmonte do sistema nacional em Brasil: a construção interrompida; e, por último, e) serão apontados alguns equívocos nas análises de Furtado.

\section{O AMBIENTE FÉRTIL E AS INFLUÊNCIAS}

Furtado escreveu suas principais obras num dos períodos mais férteis para a intelectualidade latino-americana: os anos 50 e 60. Período influenciado pelos "anos de alta teoria" nas décadas de 20 e 30, quando a ortodoxia foi traída

* Doutorando junto ao Instituto de Economia da Unicamp (Universidade Estadual de Campinas). Professor do Departamento de Economia da Unesc (Universidade do Extremo Sul Catarinense) e da Unisul (Universidade do Sul de Santa Catarina). 
pelo seu fiel escudeiro: o mercado. Foi justamente nesse período que Keynes produziu abalos sísmicos nas academias, que mais tarde repercutiram nas esferas governamentais. No pós-45, tanto no centro como na periferia, as políticas ortodoxas cederam lugar às práticas intervencionistas; os Estados nacionais passaram a orientar e gerenciar a ordem econômica por meio de políticas fiscais, monetárias, cambiais, tarifárias e de rendas; após décadas de desordem financeira causada pela implosão do fictício padrão-ouro, a moeda tornou-se um ativo gerenciado por órgãos reguladores, ou seja, o mercado estava sendo domado.

Na América Latina pós-30, a industrialização estava na ordem do dia - industrialização intencionalmente conduzida pelo Estado -, pois, por um lado, as demandas sociais aumentavam exponencialmente e contentemente se presenciava estrangulamento na oferta nos setores que demandavam recursos vultosos; por outro lado, havia uma inércia empresarial. O nacionaldesenvolvimentismo ganhava força, não apenas no Brasil de Vargas e Juscelino, mas no México de Cárdenas e na Argentina de Perón e, no outro continente, na Índia de Nehuro e no Egito de Nasser. Nesse bojo, a Cepal (Comissão Econômica para a América Latina e Caribe) se apresentava como órgão fornecedor de quadros e idéias desenvolvimentistas aos governos latinos. Foi o momento em que "estávamos pensando com nossas cabeças", dizia Prebisch a Furtado.

No meio desse ambiente efervescente, Furtado desenvolveu suas idéias. Para definir as bases do pensamento de Celso Furtado, primeiro deve-se ter em mente o cenário propício às transformações estruturais, para depois centrar o foco na sua carreira de político e de cientista social. Celso Furtado - leitor de $O$ catecismo positivista na adolescência - formou-se em Direito em 1944, pela Faculdade Nacional de Direito - Universidade do Brasil -, mas logo voltou seus estudos para a economia quando começou a ler os New Dealers. Em 1948, obteve o título de doutor em economia pela Universidade de Paris com a tese L'Économie coloniale brésilienne. Entre 1949 e 1953, trabalhou na Cepal juntamente com Prebisch na elaboração das teses cepalinas e em diagnósticos e projetos de desenvolvimento. Em 1954 e 1955, trabalhou no Grupo Misto Cepal/BNDE (Banco Nacional de Desenvolvimento Econômico) e, em 1957 e 1958, chefiou o GTDN (Grupo de Trabalho para o Desenvolvimento do Nordeste), trabalho que deu origem à Sudene (Superintendência para o Desenvolvimento do Nordeste), órgão que presidiu de 1959 a 1962. Deixou a Sudene para assumir o Ministério Extraordinário para o Planejamento do governo João Goulart, permanecendo no cargo até 1963, quando retornou à Sudene. Em abril de 1964, na calada da noite, seus direitos políticos foram cassados pela ditadura militar. Retornou ao Brasil no início dos anos 80 e, no governo José Sarney, assumiu o Ministério da Cultura. Do cargo na Cepal (em 1949), passando pelo Ministério (em 1963) até Brasil: a construção interrompida (1992), Furtado conjugou a sua vida prática com a 
carreira de intelectual, influenciou e foi influenciado pelas mudanças estruturais ocorridas no Brasil.

Inicialmente Furtado foi influenciado pelos ideais positivistas. A crença na ciência neutra e na técnica como verdadeiros instrumentos de reversão das estruturas atrasadas. As atitudes racionais e a boa vontade dos homens públicos conduziriam inevitavelmente ao progresso material.

No entanto, não há dúvidas que Raul Prebisch foi o grande mentor intelectual de Furtado. Prebisch foi um homem público que negou seu passado ortodoxo diante das atrocidades causadas pelo mercado durante os anos 30. Além de Prebisch, J. M. Keynes foi outro grande autor a influenciá-lo. Com Marx, por intermédio de Karl Mannheim, o homem da sociologia do conhecimento, Furtado despertou interesse pela história enquanto processo. Pode-se ainda citar Friedrich List, percursor da Escola Histórica Alemã, crítico da universalização da Escola Clássica e defensor do protecionismo como cimento para construção da nação; François Perroux, seu professor em Paris e formulador da teoria sobre pólo de desenvolvimento; Gunnar Myrdal e a escola sueca e John Robinson e o circulo de Cambridge dos anos 50. Cabe destacar que para entender a formação econômica do Brasil, Furtado foi iluminado pelos clássicos da "geração de trinta": Caio Prado Jr., Gilberto Freyre e Sérgio Buarque de Holanda. O que Furtado tem em comum com eles, é a lógica das transformações estruturais da sociedade brasileira que marca profundamente a formação cultural do país. Além disso, todos têm uma inserção na história com vias diferenciadas e um olhar para o futuro: Caio Prado Jr. pela economia, Gilberto Freyre pela cultura e antropologia e Sérgio Buarque pela cultura. Portanto, a força do pensamento de Furtado está na conjugação entre a Cepal e o pensamento social brasileiro.

A contribuição de Furtado à historiografia econômica brasileira pode ser observada pela forte influência que suas obras tiveram na formação de uma nova geração de cientistas sociais nos anos 60 e 70. Segundo Oliveira, "após a publicação de Formação econômica do Brasil, Furtado converteu-se em demiurgo do Brasil. Ninguém, nestes anos, pensou o Brasil a não ser nos termos furtadianos".

Formação econômica do Brasil constitui-se num livro-fonte, é a junção de keynesianos, Cepal e pensamento social brasileiro, na qual se buscam as raízes do atraso do país e a formação do mercado interno após o "deslocamento do centro dinâmico" da economia cafeeira-exportadora para a economia urbanoindustrial. O método utilizado, segundo o próprio autor, era "aproximar a História (visão global) da análise econômica; extrair desta perguntas precisas e obter respostas para a mesma História".

O livro tornou-se fonte de várias interpretações, seja para reafirmar as teses cepalinas, seja para desenvolver outras análises sobre a América Latina, 
como a teoria da dependência, ou para fazer novas leituras sobre a industrialização brasileira, como a tese do capitalismo tardio. Para citar alguns exemplos: a) a tese de Maria da Conceição Tavares, sobre o processo de substituição de importação e problemas com os estrangulamentos causados pela baixa capacidade para importar e a insuficiência de poupança, tem como fonte a Cepal e Furtado; b) o texto de Carlos Lessa, que analisa os quinze anos de política econômica no Brasil (1948-63). Lessa divide o período em duas fases: a industrialização não-intencional (1948-50), quando a política cambial se constituía no maior instrumento de política industrial, e a intencional (1950-63), quando o Estado passou a conduzir a industrialização. Baseou-se nas análises de Furtado, para quem a política cambial do pós-guerra "teve como efeito não-buscado favorecer amplamente as inversões no setor produtivo ligado ao mercado interno"; c) a tese de Wilson Cano, que discute a concentração regional no Sudeste e a integração nacional comandada a partir de São Paulo e busca subsídios nos capítulos finais de Formação. Atualmente, no Brasil, a Unicamp (Universidade Estadual de Campinas) e UFRJ (Universidade Federal do Rio de Janeiro) concentram a maioria dos pesquisadores formados na Cepal, uns reproduzindo, outros reformulando e outros negando a atual orientação ideológica do órgão.

Além da influência e do impacto causado por Formação, o livro Desenvolvimento e subdesenvolvimento também influenciou não somente uma geração nacional, mas teve repercussão internacional, tanto no centro como na periferia. A análise de Furtado sobre os problemas e as raízes do subdesenvolvimento e as maneiras de suplantá-los por meio da industrialização, revertendo as estruturas tecnológicas heterogêneas, fizeram parte dos programas de governos de vários países da periferia.

As crenças de Furtado estavam caminhando paralelamente às mudanças estruturais. Influenciado pela teoria da dependência e decepcionado com os resultados da rápida industrialização na periferia, no final dos anos 60, Furtado começou a rever suas conclusões, que estão em Um projeto para o Brasil, Análise do "modelo" brasileiro e $O$ mito do desenvolvimento econômico. Com isso, novamente outra geração de cientistas sociais começou a buscar em Furtado fundamentos e explicações para o aprofundamento da concentração de renda, o consumismo e os privilégios das elites, fenômenos que tomaram formas explícitas no Brasil a partir do golpe de 64 .

Portanto, sua contribuição para a historiografia econômica é vasta e impactante. Para compreender a história dos últimos 50 anos do Brasil, a industrialização, o subdesenvolvimento e a dependência cultural, economistas e historiadores necessariamente têm que passar por Furtado. 


\section{AS CRENÇAS E AS DESILUSÕES DE FURTADO: DAS RAÍZES DO SUBDESENVOLVIMENTO À DEPENDÊNCIA CULTURAL.}

Antes de entrar no pensamento de Celso Furtado, se faz mister uma visão geral do pensamento de Prebisch e por extensão da Cepal. No Estudio económico de la América Latina 1948 e no de 1949, Prebisch montou o esquema teórico-analítico da Cepal. Na visão de Prebisch, para o conjunto da América Latina, a velha divisão internacional do trabalho, baseada nas "vantagens comparativas", levou à deterioração dos termos de troca, com desvantagens para a América Latina, que viu seu excedente sendo apropriado pelo centro. $\mathrm{O}$ diagnóstico que ele fazia era o seguinte: os países periféricos tinham estruturas produtivas diferentes em relação ao centro, porque a inserção da periferia na Revolução Industrial deu-se de forma atrasada, tornando-a dependente e reflexa. $\mathrm{O}$ centro tinha estrutura industrial homogênea e diversificada e a periferia heterogênea, com um setor moderno e outro atrasado, e especializada, primárioexportadora. $\mathrm{O}$ moderno era formado pelo setor exportador, que se comportava dinamicamente conforme a demanda externa e era altamente especializado, era composto por produtos primários de produção agrícola ou extração mineral. $\mathrm{O}$ setor atrasado era composto pela agricultura que abastecia as cidades e pela agricultura de subsistência. Não havia uma relação articulada entre os dois setores, pelo contrário, o atrasado tornou-se um entrave ao livre desenvolvimento do moderno. A única maneira de romper com essa estrutura dual seria a industrialização e a reforma agrária. Segundo Oliveira, ao contrário de Trostski, o desenvolvimento na periferia é desigual mas não é combinado. Dai brotam as teorias do subdesenvolvimento e da economia dependente.

Diante desse quadro, Furtado começou esboçar uma nova abordagem teórica que se ajustasse à história econômica do Brasil. E para saber a razão por que o país é subdesenvolvido, onde estão as raízes do nosso atraso e por que nações mais jovens que o Brasil conseguiram se desenvolver com mais rapidez (neste caso os Estados Unidos), Celso Furtado escreveu Formação econômica do Brasil e, no final do livro, chegou à conclusão de que para reverter o quadro de subdesenvolvimento, o Brasil obrigatoriamente teria que industrializar-se e integrar suas economias regionais via formação do mercado interno. Há de se ressaltar que nesse livro o autor buscou "a análise dos processos econômicos e não reconstituição de eventos históricos que estão por trás desses processos", o que o torna um livro de economia retrospectiva e não de história econômica, pois a preocupação são os "processos econômicos", e a história serve como instrumento para entendê-los. A formação econômica do Brasil é a formação do sistema 
nacional de economia, que se completa quando o Estado-nação passa a controlar os meios e os fins da economia e condiciona a divisão social do trabalho aos interesses e à dinâmica interna do sistema. Segundo Bielschowsky, "a obra deve ser vista, na verdade, muito mais como um ensaio de interpretações históricoanalíticas de orientação estruturalista e keynesiana do que uma pesquisa histórica em grande profundidade." Formação econômica do Brasil, teve como base A economia brasileira, de 1954, e sua tese de doutorado sobre a economia colonial. A economia brasileira enfoca três pontos centrais: "a teoria do desenvolvimento: gênese histórica e mecanismos de acumulação; b) a economia brasileira: perspectiva histórica e problemas atuais; e c) crítica das idéias sobre desenvolvimento econômico." (FURTADO, 1985)

Formação econômica do Brasil é dividido em cinco períodos. Nos três primeiros (ocupação territorial, economia escravista de agricultura tropical e economia escravista mineira), o autor buscou as raízes do subdesenvolvimento. Tanto na economia escravista de agricultura tropical como na mineira, a alta concentração de renda, a baixa circulação monetária, a carência de bases técnicas e a baixa produtividade do trabalho eram constantes. $\mathrm{Na}$ agricultura tropical, o excedente era apropriado pelo senhor de engenho que concentrava $95 \%$ da renda, investindo-a parte na aquisição de equipamentos e escravos e outra parte na compra de mercadorias importadas; em ambos os casos a acumulação era cêntrica e o vínculo se dava com o exterior. Os escravos e a população livre não faziam parte do fluxo da renda. A pecuária era acessória e oscilava de acordo com o desempenho do açúcar, portanto não tinha vida própria. Numa economia com alta concentração de renda e escravista, a circulação monetária é insignificante, inibindo a acumulação pulverizada geradora de concorrência. Como resultado, além do desinteresse de Portugal, havia uma carência de base técnica, com o uso de instrumentos rudimentares (o complexo do engenho manteve a mesma estrutura técnica por séculos) e, anacronismo à parte, baixo índice de competitividade. A América Portuguesa dominou o mercado do açúcar até o surgimento das Antilhas como concorrente, a partir de 1650. Desse momento em diante, a economia de agricultura tropical entrou num processo secular de estagnação e decadência.

A economia escravista mineira também padeceu dos mesmos problemas. Entre 1700 e 1765, uma leva considerável de imigrantes aventureiros, ávidos a explorar os metais preciosos, entrou na colônia. Como havia de se esperar, em função do esgotamento das jazidas e da extração irracional, causada pela carência de bases técnicas, a região das Minas Gerias passou por um atrofiamento econômico (em especial o monetário) e social jamais visto na história americana. A dispersão populacional formou as economias de subsistência, com baixíssima produtividade de trabalho, as quais involuíam, e seus membros ficavam à mercê de senhores déspotas, que, mais tarde, os utilizariam apenas como serviçais e 
eleitores nas farsas eleitorais.

Na economia de transição para o trabalho assalariado, quarto período, Furtado estabeleceu dois momentos: de 1775 a 1850 - a longa espera -, período de estagnação com queda na atividade agrícola, na pecuária e na mineração (porém destaca a gestação da economia cafeeira); e de 1850 a 1888, quando o problema da mão-de-obra aflorou em função da sua oferta inelástica, decorrente do fim do tráfico e do desprezo aos braços nacionais. A implantação da economia assalariada tornou o fluxo da renda completo. Como a economia cafeeira foi implantada sobre uma base com estruturas arcaicas (grande propriedade e agricultura especializada), o modelo primário-exportador continuou persistindo na economia brasileira, cujo lado dinâmico sempre foi o externo e o maior indutor da renda até final dos anos 20 .

A estrutura montada até 1930, segundo Furtado, não permitia o desenvolvimento do mercado interno, apesar do impulso pós-1918, pois a renda continuava ainda muito concentrada, as economias regionais estavam desintegradas e o potencial industrial era insignificante. Como não havia base técnica forte e diversificada, a produtividade do trabalho também era baixa, entravando ainda mais a desconcentração da renda. Segundo Bielschowsky, em Formação, "a análise está centrada na identificação dos mecanismos de expansão do nível de renda e dos desequilíbrios estruturais". Somente com a integração do mercado interno e a industrialização comandada a partir do Estado - o único agente capaz de liberar as forças produtivas - é que o país poderia sair da sua condição de periferia e se colocar num patamar mais elevado, junto às nações mais desenvolvidas. É bom lembrar que Furtado publicou Formação em 1959, no bojo do Plano de Metas, quando a estrutura produtiva estava se alterando, porém a estrutura agrária e a mentalidade aventureira das elites dominantes continuava nos moldes anteriores a 1930.

Sobre as análises das estruturas subdesenvolvidas, Furtado as detalhou em Desenvolvimento e subdesenvolvimento, o livro que é resultado de vários artigos publicados ao longo da década de 50. Nessa obra, está estampada sua crença na possibilidade da reversão das estruturas tecnológicas heterogêneas como o caminho seguro para o desenvolvimento. Segundo Furtado, o processo de desenvolvimento se dá por meio de combinações das técnicas existentes com a introdução de novas que tendem a aumentar a produtividade do trabalho, aumentando a renda social e alterando a composição da demanda. Portanto, o desenvolvimento econômico é um processo de acumulação de capital e, sem o progresso técnico, a acumulação encontra seus limites. Por exemplo, a insuficiência de setores básicos na economia, como siderurgia, transporte e energia, pode levar a uma deficiência produtiva (falta de insumos) em outros setores, como na agricultura, bens de consumo duráveis e, sobretudo, no núcleo do sistema, o 
setor de bens de capital.

Para Furtado, o desenvolvimento econômico é um processo profundamente desigual, "surge em uns pontos, propaga-se com menor ou maior facilidade em outros, toma vigor em determinados lugares, aborta noutros etc." Furtado historiciza o conceito e conclui que o "subdesenvolvimento é um processo autônomo e não uma etapa pela qual tenham necessariamente passado as economias que já alcançaram grau superior de desenvolvimento"; o que no fundo é uma crítica à visão etapista de Rostow. Há um resultado histórico da evolução da economia mundial desde a Revolução Industrial, que teve como berço a Inglaterra e a difusão se deu primeiro para o continente (França, Alemanha e Itália), quando as técnicas tinham um poder de difusão e assimilação muito alto. Estados Unidos, Canadá e Austrália foram o segundo bloco de países beneficiados com a difusão da industrialização européia, permitida graças à revolução nos transportes. O terceiro bloco a industrializar-se foram as regiões periféricas, onde já havia alta densidade demográfica e estrutura pré-capitalista, incluso o Brasil. Na primeira etapa do desenvolvimento industrial nos países europeus, nos Estados Unidos, no Canadá e na Austrália, a característica marcante foi a introdução de elementos dinâmicos na estrutura da oferta. Na segunda etapa, no desenvolvimento induzido da periferia, a procura de manufaturas foi suprida com importações e a demanda era o elemento dinâmico. Somente quando houve problemas com o lado externo (Grande Depressão e Segunda Guerra Mundial), a procura passou a ser lentamente substituída no âmbito interno, deslocando o centro dinâmico para o mercado interno. Segundo Furtado, "a etapa superior do subdesenvolvimento é alcançada quando se diversifica o núcleo industrial e este fica capacitado a produzir parte dos equipamentos requeridos pela expansão da sua capacidade produtiva."

Onde residia o problema da industrialização? Residia na insuficiência de poupança (visão neoclássica) e de capacidade para importar. Como havia dependência muito grande de manufaturados do exterior, era necessário substituílos para completar o parque industrial. Só que, a cada nova substituição, novas demandas surgiam e se exigia mais capacidade para financiar importações mais caras, causando problemas no Balanço de Pagamentos e alimentando a espiral inflacionária. Sendo assim, como a oferta era rígida e a demanda alta e móvel, a cada nova etapa do processo de substituição de importação, o estrangulamento externo se repunha. Isso se dava porque o processo de industrialização avançava com muita rapidez e estava calcado sobre estruturas arcaicas. Então, como reverter o subdesenvolvimento? Já que a heterogeneidade tecnológica entre os diversos setores da economia é que caracterizava o subdesenvolvimento, bastava apenas introduzir novas técnicas e combiná-las com as antigas por meio da industrialização. Como resultado, teria-se o aumento da produtividade do trabalho, trazendo ganhos sociais. Pelo lado agrário, se fazia urgente uma reforma agrária, 
para conter o êxodo rural, pois este pressionava os salários urbanos para baixo, concentrando ainda mais a renda. Ambas, industrialização e reforma agrária, deveriam ser comandadas pelo Estado, o único ente com recursos financeiros capaz de alavancar o desenvolvimento.

Claramente pode-se perceber a crença que Furtado tinha na técnica. A industrialização seria a "tábua salvadora" da periferia, onde uma população considerável estava à margem da sociedade, sem acesso ao mercado de consumo e sem o mínimo de proteção social.

Após um período no exílio, fazendo novas reflexões, Celso Furtado voltou ao Brasil no final dos anos 60 para proferir algumas palestras e se deparou com os primeiros resultados concretos da industrialização dos anos 50, das reformas monetárias e fiscais de 1965/1966, e com o início de um novo período expansivo, o "milagre econômico". Suas crenças transformam-se em ilusões perdidas. Em 1968, publicou Um projeto para o Brasil, resultado de conferências proferidas junto à Comissão de Economia da Câmara dos Deputados e ao Instituto de Estudos Internacionais da Universidade do Chile. Foi um primeiro ensaio em direção às mudanças que Furtado assumiria mais tarde em Análise e em $O$ mito. Nesse livro, Furtado começou a rever suas crenças em relação às possibilidades de reverter os quadro desolador de subdesenvolvimento na periferia e incorporou questões subjetivas e políticas. Foi o início das desilusões. Segundo o autor, "o desenvolvimento não é uma simples questão de aumento de oferta de bens ou de acumulação de capital, possui ele um sentido, é um conjunto de respostas a um projeto de autotransformação de uma coletividade humana." No entanto, nesse momento Furtado ainda acreditava na possibilidade de reversão do subdesenvolvimento mediante reformas na estrutura social e econômica, que proporcionariam à camada menos favorecida entrada no mercado de consumo, ou seja, o consumismo popular. Reformas como: mudança da estrutura da renda, reorientação do processo produtivo, reforma agrária, solucionar a insuficiência da capacidade para importar e rever o poder de comando das empresas transnacionais. Suas desilusões estão mais explícitas em Análise do "modelo" brasileiro, publicado em 1972, e tomam forma acabada em $O$ mito do desenvolvimento econômico, 1974, discutindo em ambos o problema da dependência cultural e do consumismo.

Em Análise, Furtado começou com um vôo panorâmico sobre o Brasil e apontou as seguintes características: a) economia subdesenvolvida; b) agricultura com baixa produtividade; c) setor manufatureiro moderno com tecnologias importadas e controladas por grupos estrangeiros; d) Estado como fonte principal de acumulação. O principal problema que o país enfrenta, segundo o autor, é o de "gerar fontes de emprego para sua numerosa e crescente população, grande parte da qual vegeta em setores urbanos marginalizados ou na agricultura de 
subsistência." Quando ocorre um novo investimento, ele é poupador de mão-deobra e voltado para atender uma elite consumista. O que se tem no Brasil é a modernização dos padrões de consumo e não da estrutura produtiva, ou seja, da demanda, e não da oferta. A industrialização brasileira foi feita numa base com a renda concentrada, pré-30, e, ao invés de reverter o quadro, ela apenas o ampliou, aprofundando ainda mais as disparidades sociais. Sendo assim, assistiu-se, no período 1930-1970, apenas a mudanças nos padrões de consumo, pois a elevação da produtividade não tinha assimilação concomitante ao processo produtivo. Apenas um segmento da sociedade passou a desfrutar dos benefícios trazidos pela industrialização, um segmento que já era beneficiado antes dos anos $30 \mathrm{com}$ os importados. As substituições de importados foram sendo feitas para atender a essa demanda e concentraram-se, sobretudo, na produção de bens de consumo duráveis que satisfaziam às necessidades de uma elite cosmopolita.

No Brasil não houve - e não há - relação direta entre salário e produtividade. A relação ocorreu apenas nos setores mais modernos, onde as classes média e a média alta se concentravam, pois, na massa assalariada, a pressão da oferta elástica de mão-de-obra, causada principalmente pelo êxodo rural e pela repressão sindical por parte dos governos militares, estava garantindo a concentração de renda, permitindo a reprodução do sistema industrial concentrador. Todas as reformas postas em marcha a partir de 1964 tiveram o objetivo de concentrar ainda mais a renda e favorecer o consumo conspícuo: reformas como a neutralização da inflação via correção monetária, o crédito ao consumo e o financiamento à construção civil, todas voltadas à classe média. Resumindo: no Brasil houve alta incorporação do progresso técnico e baixa difusão desse progresso ao conjunto da população

Em $O$ mito, Furtado centra-se mais na imitação dos estilos de vida, à la Gilberto Freyre, seguidos por uma elite consumista e individualista e, poderiase acrescentar, utilitarista e narcisista, que sempre se espelhou nos padrões de consumo internacionais. Ele começa perguntando se o desenvolvimento pode ser generalizado para todos os povos do planeta e conclui que não são os problemas populacionais ou dos recursos não-renováveis que inibem a generalização do desenvolvimento, mas, sim, o fato de que uma elite não abre mão de seu consumo suntuoso, sobretudo na periferia, onde a dependência cultural assume formas mais claras. De acordo com Furtado,

o comportamento dos grupos que se apropriam do excedente, condicionado que é pela situação de dependência cultural em que se encontram, tende a agravar as desigualdades sociais, em função do avanço na acumulação. Assim, reprodução das formas sociais, que identificamos com subdesenvolvimento, está ligada às formas de comportamento condicionadas pela dependência. 
A modernização dos padrões de consumo e a imitação dos estilos de vida cria um circulo vicioso que aprofunda ainda mais o subdesenvolvimento. Para a elite manter-se moderna, ela apenas imita o comportamento das elites cêntricas, o que obriga mudanças na estrutura produtiva que necessariamente devem adaptar-se a este novo estilo. Sendo assim, o crescimento industrial não supera o subdesenvolvimento e a dependência. Segundo Furtado, "toda economia subdesenvolvida é necessariamente dependente, pois o subdesenvolvimento é uma criação da situação de dependência" e o "fenômeno da dependência se manifesta inicialmente sob a forma de imposição externa de padrões que somente podem ser mantidos mediante a geração de um excedente criado no comércio exterior. É a rápida diversificação desse setor do consumo que transforma a dependência em algo dificilmente reversível". As classes mais abastadas não abrem mão de seus privilégios e o excedente é aplicado cada vez mais na modernização dos padrões de consumo, sem alterar profundamente a estrutura da renda. Com isso, amplia-se ainda mais o fosso que separa ricos de pobres. Portanto, dentro dos marcos da dependência é impossível o desenvolvimento, tornando-o um mito.

A industrialização impulsiona a formação de um sistema nacional de economia, porém, no Brasil, esse sistema está incompleto porque deu-se dentro dos marcos do subdesenvolvimento. Os limites à construção da nação são dados pela lógica adaptativa do parque industrial, isto é, o processo de industrialização fica a reboque da lógica adaptativa da modernização dos padrões de consumo, dos estilos de vida da elite. O resultado é um desenvolvimento descontínuo que vai aos solavancos e não supera o caráter dependente da economia.

As crenças e as ilusões de Furtado começaram a se desvanecer no ar e tomaram forma acabada em Brasil: a construção interrompida, livro publicado em 1992, no qual claramente se percebe o desabafo de um intelectual desiludido e angustiado com o futuro do Brasil. O projeto neoliberal implantado no Brasil, a partir de 1990, abortou a construção da nação sem que esta cumprisse sua função histórica de redução das disparidades sociais e regionais, garantindo ao seu povo emprego e proteção social, a despeito da lógica do mercado. Interrompeu-se precocemente a construção de um sistema nacional de economia que estava sendo consolidado via integração do mercado interno e industrialização, ou seja, interrompeu-se a formação econômica do Brasil. Para Furtado, "um sistema econômico nacional não é outra coisa senão a prevalência de critérios políticos que permitem superar a rigidez da lógica econômica na busca do bem-estar coletivo". Porém, o sistema nacional começou a ser desarticulado, fazendo desaparecer sua sinergia interna, e a integração passou a ser preferencialmente voltada à economia internacional. Afinal, quem são os responsáveis por esta desarticulação? Segundo Furtado, são as transnacionais, o grande capital financeiro e o grupo dos países mais ricos que atuam com "forças desarticuladoras do sistema 
nacional". Essas "forças" colocam duas opções ao Brasil: ou adapta-se à nova ordem internacional ou torna-se um anacronismo histórico. Diante da atual mundialização do capital, Furtado conclui que, se foi atribuida às empresas transnacionais "a iniciativa do estilo de desenvolvimento, caminharemos inexoravelmente para a desarticulação do sistema econômico nacional".

Neste livro, Furtado assume uma postura humanista, acredita na vontade humana, se preocupa com as questões ecológicas e faz elogios às Nações Unidas.

Cabe destacar que Furtado continua acreditando na incorporação e na difusão do progresso técnico como caminho para aumentar a produtividade e ampliar os ganhos sociais. Então pode-se concluir que Furtado manteve as mesmas crenças na técnica, o problema está no processo de assimilação. Resumindo: o problema reside no processo social e político de assimilação ampla do progresso tecnológico. Sua desilusão é em relação ao processo.

\section{EQUÍVOCOS E DESLIZES}

Um dos erros de Furtado foi não ver o vínculo orgânico que havia - e há - entre o Estado e o capital privado interno e externo. De 1930 a 1964, a chamada crise de hegemonia e de transição acomodava os interesses díspares no seio do Estado, relativizando a sua "autonomia". No capitalismo, não há Estado autônomo, há sim Estado burguês, aparelho de hegemonia da burguesia, seja ela nacional ou estrangeira. O caráter social do Estado dependerá do sentimento nacional da burguesia e do compromisso que ela tem para a formação de um sistema nacional de economia com inclusão social. Se esta burguesia for entreguista e cosmopolita, a formação do sistema fica comprometida. Furtado não via este vínculo orgânico porque, até 1964, fazia parte da estrutura estatal. Somente quando ele se afastou do Estado, começou a desenvolver a idéia de dependência cultural das elites.

Segundo Oliveira, nas bases da teoria do subdesenvolvimento há um distanciamento político das análises econômicas, o que a aproxima dos neoclássicos: "seu distanciamento político explícito procura apresentar uma teoria 'econômica' da economia, mas não da maneira de Marx, em que as relações de produção constróem a sociabilidade geral; a rigor, a política na teoria do subdesenvolvimento é um epifenômeno". Ora, esta crítica serve a qualquer autor não-marxista que faz análise do desenvolvimento e do subdesenvolvimento econômico.

Outro erro de Furtado foi acreditar que a reversão das estruturas tecnológicas heterogêneas e a incorporação nos salários dos ganhos de 
produtividade poderiam conduzir o país ao desenvolvimento. Ora, como esperar esse resultado num país que tem uma classe dominante cujo ethos é a aventura e a riqueza fácil (Sérgio Buarque de Holanda); uma classe dominante que não tem consciência nacional e vê este país como um negócio (Caio Prado Jr.); uma classe dominante e cosmopolita que sempre olha para o exterior; uma classe que usa "anel de doutor" para diferenciar-se da massa (Gilberto Freyre)? O problema era - e é-essencialmente cultural. Não consegue-se transformar as oligarquias toscas e oligarquias esclarecidas com objetivos nacionais (Oliveira Vianna). Sendo assim, esperar mudanças na consciência da classe dominante brasileira nos anos 50 era pura utopia. Afinal, ela tinha deixado de ser agrária havia apenas 20 anos e escravocrata, 60 anos. Atualmente, essa mesma classe está encantada com a globalização, com a possibilidade dirigir um carro importado e viajar constantemente para Miami.

O problema também era - e é - social, porque o único compromisso que o Estado-nação teve no Brasil foi o de conduzir a industrialização sem preocupar-se com a inclusão social. A inclusão ficou por conta da mobilidade social, tida como um projeto individual de entrada dos "de baixo" nos padrões de consumo moderno.

O problema também era - e é - político, porque o particularismo, os interesses privados controlavam a esfera estatal. Na década de 50, 64\% da população era rural, na qual ainda prevalecia o coronelismo. O Estado, muitas vezes, era extensão dos laços familiares, do compadrio, dos favores e dos privilégios.

\section{CONCLUSÃO}

Por meio destas seis obras - Formação econômica do Brasil, Desenvolvimento e subdesenvolvimento, Um projeto para o Brasil, Análise do "modelo" brasileiro, O mito do desenvolvimento econômico e Brasil: a construção interrompida -, pode-se acompanhar a trajetória do pensamento de Celso Furtado, suas crenças e desilusões. Em Formação, a origem do subdesenvolvimento; em Desenvolvimento, a crença na industrialização como "tábua de salvação" da periferia; em Análise e $O$ mito, a desilusão com relação aos resultados da industrialização num país dependente; e em Brasil: a construção interrompida, o seu "sentimento de angústia" ao ver o sonho de nação sendo desmantelado.

Numa perspectiva de longa duração, Furtado escreveu suas obras num período anômalo do capitalismo, quando a lógica econômica estava sendo temporariamente controlada pela política e os ganhos sociais aumentavam consideravelmente por meio de ações públicas. Nesses últimos vinte anos, o 
capitalismo apenas encontrou seu curso natural, ou seja, o aumento da exclusão social.

Suas crenças, suas desilusões e sua angústia fazem parte da historiografia econômica brasileira. Por aí perpassaram várias interpretações sobre a história econômica brasileira. Furtado influenciou e foi influenciado. A Cepal, a teoria da dependência e a tese do capitalismo tardio devem muito a esse economista, historiador e homem público.

\title{
RESUMO
}

Este artigo apresenta a evolução do pensamento de Celso Furtado através se seis de seus livros: Formação Econômica do Brasil, Desenvolvimento e Subdesenvolvimento, Um Projeto Para o Brasil, Análise do "Modelo" Brasileiro, O Mito do Desenvolvimento Econômico e Brasil: a construção interrompida. Estes livros revelam sua convicção e desilusão quanto à capacidade da industrialização de se mostrar a única solução para o Brasil. A trajetória começa com um projeto de Nação e termina com a dissolução do projeto pelo neoliberalismo.

\begin{abstract}
This paper presents the evolucion of the Furtado's thinking through six books: Formação econômica do Brasil, Desenvolvimento e subdesenvolvimento, Um projeto para o Brasil, Análise do "modelo" brasileiro, $O$ mito do desenvolvimento economico and Brasil: a construção interrompida. This books presents his conviction and disilluision in the industrializacion like only solution for Brazil. The trajectory begin with a project of the Nation and finish with disassemble Nation with neoliberalism.
\end{abstract}




\section{REFERÊNCIAS}

BIELSCHOWSKY, Ricardo. Pensamento econômico brasileiro: o ciclo ideológico do desenvolvimentismo. Rio de Janeiro: IPEA/INPES, 1988. (Série PNPE, 19).

FURTADO, Celso. Desenvolvimento e subdesenvolvimento. 2. ed. Rio de Janeiro: Fundo de Cultura, 1963.

. Um projeto para o Brasil. 2. ed. Rio de Janeiro: Saga, 1968.

1982. Análise do "modelo" brasileiro. 7. ed. Rio de Janeiro: Civilização Brasileira, . O mito do desenvolvimento econômico. 6. ed. Rio de Janeiro: Paz e Terra, 1983. . Auto-retrato intelectual. In: OLIVEIRA, Francisco de (Org.). Celso Furtado. São Paulo: Ática, 1983. (Coleção Grandes Cientistas Sociais, 33).

. A fantasia organizada. 3. ed. São Paulo: Paz e Terra, 1985.

. Formação econômica do Brasil. 23. ed. São Paulo: Nacional, 1989.

. Brasil: a construção interrompida. 2. ed. Rio de Janeiro: Paz e Terra, 1992.

IGLÉSIA, Francisco. História e ideologia. São Paulo: Perspectiva, 1971.

MALLORQUÍN, Carlos. O pensamento econômico latino-americano: entrevista de Celso Furtado a Carlos Mallorquín. Novos Estudos Cebrap, São Paulo, n. 41, mar. 1995.

OLIVEIRA, Francisco de. A navegação venturosa. In: OLIVEIRA, Francisco de (Org.). Celso Furtado. São Paulo: Ática, 1983. (Coleção Grande cientistas sociais, 33).

SAMPAIO Jr., Plínio S. de Arruda. Entre a nação e a barbárie: uma leitura das contribuições de Caio Prado Jr., Florestan Fernandes e Celso Furtado à crítica do capitalismo dependente. Campinas, 1997. Tese (Doutorado) - IE/Universidade Estadual de Campinas. 